\title{
ENTRE ANDANÇAS E LEMBRANÇAS: ALGUMAS REFLEXÕES SOBRE MIGRAÇÃO E HISTÓRIA ORAL*
}

\author{
Patricia Regina de Lima Silva ${ }^{1}$
}

\begin{abstract}
Resumo
O presente artigo tem como objetivo refletir algumas peculiaridades acerca da migração de mulheres nordestinas para a região Norte. Aponta a importância da congregação familiar nas decisões de partir do Nordeste em direção ao Norte. A família, nesse processo, aparece como elemento fundamental nas trajetórias dessas mulheres. Como fenômeno social, a migração ocorre numa dinâmica de relações interpessoais, que abrange uma variada gama de elementos que a particulariza em momentos vividos pelos sujeitos e que exige, de certa forma, uma análise das condições que surgem ou se processam diante da decisão de migrar. Por sua vez, a história oral aponta caminhos de análises a partir das experiências dos sujeitos tanto no âmbito individual quanto coletivo a partir dos sentidos registrados em suas memórias.
\end{abstract}

Palavras-chave: Migração; História Oral; Arranjo familiar.

\begin{abstract}
This article aims to reflect some peculiarities about the migration of northeastern women to the North region. It points out the importance of the family congregation in the decisions to leave the Northeast towards the North. In this process, the family appears as a fundamental element in the trajectories of these women. As a social phenomenon, migration occurs in a dynamic of interpersonal relationships, which encompasses a wide range of elements that particularizes it in moments experienced by the subjects and that requires, in a certain way, an analysis of the conditions that arise or are processed before the decision to migrate. In turn, oral history points to paths of analysis based on the experiences of the subjects, both individually and collectively, based on the meanings recorded in their memories.
\end{abstract}

Keywords: Migration; Oral History; Family arrangement.

\footnotetext{
* O presente artigo discute algumas considerações abordadas em minha Dissertação de Mestrado - Do espaço lembrado ao espaço vivido: narrativas orais de mulheres nordestinas em Parintins - AM, na segunda metade do século XX.

${ }^{1}$ Doutoranda em História pelo Programa de Pós-Graduação em História da Universidade Federal do Amazonas. Mestre em História Programa de Pós-Graduação em História da Universidade Federal do Amazonas. Licenciada em História pela Universidade do Estado do Amazonas - UEA. Professora de História da Rede Pública de Ensino - SEDUC AM. E-mail: prsilvahist@gmail.com
} 
Inserida na dinâmica dos deslocamentos sociais, a migração, também compreendida como fenômeno social imprime significados tanto de âmbito individual quanto coletivo na vida de todos os sujeitos que vivenciaram e ainda vivenciam o processo migratório na própria pele. Nessa direção, Lang $^{2}$ coloca que a migração é um fenômeno complexo imbuído de diferentes significados, especialmente aos de âmbito coletivo e individual. No caráter coletivo, o deslocamento tanto do lugar de onde se está saindo ou entrando, a migração pode ser analisada por meio de dados estatísticos levando em consideração os fatores atuantes tanto na atração quanto na expulsão presentes nos locais de saída e de destino.

Enquanto processos individuais ou experiência pessoal, conforme denomina aquela autora, a migração pode ser percebida como uma etapa que se desenrola por meio do trajeto que é realizado em partes, ou seja, em processos. Sendo assim, a migração caracterizada como fenômeno que emerge do ser social se constitui em espaços de deslocamentos e esses espaços não se restringem apenas ao aspecto físico, pelo contrário, se estendem ao campo do simbólico que é repleto de sentidos.

Vale ressaltar que falar de migração é considerar a complexidade existente na mesma, haja vista que não se trata de pertencer a um único campo do conhecimento, e nem poderia. Destarte, importantes abordagens têm sido realizadas em diferentes áreas das ciências humanas, exemplo disso, é a Geografia e seus estudos populacionais, a Demografia, a Sociologia, a Antropologia, sem deixar de mencionar as contribuições da própria História.

Temos com isso, uma evidência de que falar de migração é muito mais complexo do que se pensa, cada ponto de vista preocupa-se com aspectos distintos entre si, mas não desconexos. Dessa forma, é possível dizer que se trata de um processo, ou melhor, processos migratórios.

Desse pressuposto, significa dizer que, ao migrar o sujeito não está isento de exercer o seu desejo de mudar e essa mudança pode se dar em várias óticas, como moradia, cidade, estado, região ou até mesmo de país. Nesse ato de partir, o lugar de origem se apresenta como um espaço de saudade ou não, espaço que fala sobre o não conformismo de quem está saindo, a não aceitação por uma vida marcada por dificuldades, por isso a decisão de ir embora. Nesse caso, os que tomam essa decisão de

\footnotetext{
${ }^{2}$ LANG, Alice Beatriz da Silva Gordo. História oral e migração: a questão do regresso. Oralidades: Revista de História Oral, 2. 2007.
} 
sair só ou levando consigo os familiares rompem com vínculos estabelecidos e abrem caminhos na intenção de construir outros rastros de oportunidades.

E através do ato de partir ou chegar a um lugar novo, é plausível observar os sujeitos em trânsito, não precisamente levados por algo que lhe seja externo, distante. Porém, é possível perceber seu movimento em busca das suas próprias possibilidades, dos seus desejos, de novas e outras perspectivas. A migração, nesse caso e na perspectiva de Pereira ${ }^{3}$, imprime o anseio de melhorar de vida.

Na busca por uma vida melhor, Lacerda, discute as relações empreendidas pelos sujeitos frente aos seus processos migratórios, dentro de uma ampla discussão historiográfica levanta questões acerca das ações dos próprios sujeitos em partir. A autora coloca o migrante, especificamente, o nordestino cearense em relação ao Pará, como alguém que decide, como sujeito que é ativo. Norteia sua discussão basicamente em duas linhas que:

\begin{abstract}
Inicialmente trata-se das compreensões que a historiografia foi dando ao longo do tempo ao tema, cristalizando, num certo sentido, perfis dos migrantes e igualmente simplificando, numa relação de dominantes e dominados, as vivências do grupo no Pará. Um segundo aspecto é ligado à decisão do próprio migrante de se deslocar do Ceará, o que nos levou a perceber que, longe desse ter sido uma decisão apenas dos poderes públicos do Ceará e do Pará, os atingidos pelas secas também exprimiam seu interesse ou não de sair do sertão $0^{4}$.
\end{abstract}

Vale destacar que essa abordagem feita por Lacerda diz respeito aos deslocamentos propagados e financiados via estatal durante o período áureo da borracha. Contudo, auxilia compreendermos de que maneira o contato entre esses dois mundos distantes e distintos entre si, vão ficando cada vez mais próximos e entrelaçados. Assim, podemos afirmar que as causas incutidas na migração muitas vezes, são colocadas sob aspectos gerais das condições socioeconômicas e dentro de uma perspectiva regional, extrapola essa forma de pensar, vai além, a migração passa a ser estudada não apenas como fenômeno meramente ligado às implicações geográficas e suas circunstâncias, ela passa a ser eminentemente, social. E o contato entre Norte e Nordeste torna-se inevitável.

\footnotetext{
${ }^{3}$ PEREIRA, José Carlos Alves. O lugar desmanchado, o lugar recriado? Enredos e desenredos de jovens rurais na migração internacional. Campinas, 2012. Tese (doutorado) - Programa de Pós-Graduação em Sociologia - Instituto de Filosofia e Ciências Humanas da Universidade Estadual de Campinas - SP.

${ }^{4}$ LACERDA, Franciane Gama. Migrantes cearenses no Pará: faces da sobrevivência (1889 - 1916). Belém: Ed. Açaí/Programa de Pós-graduação em História Social da Amazônia (UFPA) / Centro de Memória da Amazônia (UFPA), 2010.
} 
De um lado o Nordeste como espaço de saída, do outro o Norte, como espaço de entrada. Nesse aspecto, a Amazônia, se configura como palco e cenário do entrelaçamento, físico, geográfico, econômico, cultural e social. Temos aqui, dois mundos que se cruzam, se fundem e se diferenciam.

Esse entrelaçamento é bastante visível em Arthur Reis ${ }^{5}$, na sua obra o Seringueiro e o Seringal, onde discorre sobre o contato estabelecido entre nordestinos e amazônidas e, de que maneira, essa fusão vai paulatinamente modificando os hábitos, a linguagem, as formas de perceberem o mundo dentro de uma perspectiva religiosa em que de um lado há uma cosmovisão pautada no catolicismo e do outro uma indígena, ambas não deixam de existir e nem de fazer-se, apenas se transformam. Diante disso, novos arranjos sociais são constituídos na Amazônia, no Amazonas, em especial na cidade de Parintins ${ }^{6}$ (localizada aproximadamente à $370 \mathrm{Km}$, está à margem direita do rio Amazonas e à leste da capital, Manaus) como exemplo a partir das mulheres que contribuíram na realização desse estudo. Desse modo, podemos afirmar que a participação feminina marcou e ainda marca importantes fluxos migratórios na dinâmica social brasileira, é notório concordar com Chaves ao mencionar que:

A invisibilidade das mulheres nos estudos de migração tem suas raízes na prevalência de certo descaso no que diz respeito à importância da condição social feminina, acrescida de certo vagar na incorporação de mudanças que acontecem desde pelo menos os anos 70 no status e papel da mulher na sociedade ${ }^{7}$.

Sobre isso, Bassanezi, enuncia que:

\begin{abstract}
"Migrar é coisa para homem", costuma-se dizer sem pensar, sem atentar para estatísticas, fotos, depoimentos, histórias de famílias. Sim, as migrantes têm uma história. Desde sempre elas têm migrado, frequentemente na companhia de familiares, amigos e conhecidos em busca de melhores condições de vida e trabalho, mas migram também sozinhas, não só à procura de emprego, mas de independência, de casamento, ou até para fugir de discriminações e violências ${ }^{8}$.
\end{abstract}

\footnotetext{
${ }^{5}$ REIS, Arthur Cezar Ferreira. O Seringueiro e o Seringal. Ed. do serv. de Informação Agrícola, série Documentário da Vida Rural (5). Rio de Janeiro. Serv. Graf. Ibge, 1953.

${ }^{6}$ Parintins, também, bastante conhecida pela disputa ocorrida entre as agremiações folclóricas dos boisbumbás Garantido representado nas cores vermelho e branco e Caprichoso representado nas cores azul e branco que acontece todo último final de semana do mês junho. Em virtude da pandemia do novo coronavírus a edição 2020 foi suspensa.

${ }^{7}$ CHAVES, Maria de Fátima Guedes. Mulheres migrantes: senhoras de seu destino? Uma análise da migração interna feminina no Brasil: 1981 - 1991. São Paulo, 2009, p.14. Tese (doutorado) - Universidade Estadual de Campinas - Departamento de Demografia - Instituto de Filosofia e Ciências Humanas. Disponível na biblioteca digital da Unicamp.

${ }^{8}$ BASSANEZI, Maria Sílvia. Mulheres que vêm, mulheres que vão. IN: PINSKY, Carla Bassanezi; PEDRO, Joana Maria. Nova História das mulheres no Brasil. 1 ed. São Paulo: Contexto, 2013.
} 
Com isso, se faz necessário discutir sobre o papel desempenhado pelas mulheres diante de seus processos migratórios, ou seja, abordar a temática da migração pelo viés feminino é fazer com que essa perspectiva seja vista como objeto de análise, levando em consideração dentre tantos, os motivos que as fizeram partir.

É preciso salientar que o Nordeste brasileiro durante muitos anos foi e continua sendo mostrado como um grande fornecedor de mão-de-obra para outras regiões do país, especialmente o Norte. Djalma Batista em "O Complexo da Amazônia" afirma que foi "o mais numeroso de todos" 9 . Em que movidos pelos incentivos governamentais tais sujeitos partiram em busca de novas perspectivas de vida. Com isso adentraram em novos cenários sociais em sua maioria contrastantes entre imaginário sonhados no Nordeste e realidades vivenciadas na Amazônia.

A historiografia tradicional brasileira aponta dois grandes momentos de migrações nordestinas para Amazônia, ocorridas no final do século XIX e início do século XX, que se referem às muitas políticas governamentais de incentivo à migração para esta região. Um exemplo disso aconteceu a partir da segunda metade do século XIX no contexto da extração da borracha, quando a mão-de-obra estava quase que totalmente envolvida na sua vazão.

Tal política repetiu-se ao longo do século XX no esforço de guerra conhecido como batalha da borracha (1942-1945), quando o governo brasileiro em parceria com os Estados Unidos induz com suas políticas a vinda de muitos nordestinos para a região amazônica. Essa política, caracterizada como projeto de modernidade para Amazônia elaborada no governo de Getúlio Vargas (Estado Novo) tinha como meta, também fazer com que a região "pertença" ao restante do país.

As ações intervencionistas feitas pelo governo sob o discurso de desenvolver a Amazônia não é uma prática visível apenas nas décadas passadas, mas que permeia até hoje. E mesmo o Estado incentivando ou desestimulando a migração para a região de maneira oficial, ela continua acontecendo constantemente.

As experiências vividas marcaram e marcam as trajetórias de homens e mulheres advindos do Nordeste para o interior da Amazônia. A distância do lugar de origem vai sendo diminuída a partir das vivências que vão sendo ressignificadas pelas memórias. Assim, novas experiências surgem e se transformam nas vidas desses sujeitos. Essas

${ }^{9}$ BATISTA, Djalma. O complexo da Amazônia - análise do processo de desenvolvimento. 2 ed. Manaus: Editora Valer, Edua e Inpa, 2007. 
novas experiências, por sua vez, ocorrem dentro de uma tensão entre o que é incorporado, as novas apropriações que vão sendo agregadas cotidianamente, em relação ao que é objetivado, ou seja, as disputas ocorridas dentro do novo espaço social.

O novo lugar entra em disputa a partir da migração. Uma nova relação social se constitui, torna-se ainda mais dinâmica. Pensar na dinamicidade existente nas relações estabelecidas entre o sujeito/cidade e cidade/sujeito e de que maneira essa atitude citadina vai sendo apropriada pelos próprios sujeitos que cotidianamente transitam em seus espaços, nos faz refletir em José D’Assunção Barros, em seu livro Cidade e História, ao analisar as diferentes atribuições sobre a cidade, afirma que esta foi apontada como artefato cultural, corpo, obra de arte, etc. Contudo, enfatiza a cidade como texto, e este em duas dimensões, o texto que pode ser lido e o que pode ser escrito ${ }^{10}$.

A cidade como texto que pode ser lido diz respeito aos deslocamentos feitos dentro dela, as inúmeras idas e vindas de pessoas no fluxo diário. Cada pessoa tem uma forma de apreender cada monumento construído. O som, o cheiro, a cor, o movimento, também são internalizados diferentemente pelo sujeito que caminha por ela, e externalizados de maneira peculiar, possibilitando que aspectos sociais sejam estabelecidos em expressões de cidadania.

Como texto que pode ser escrito, refere-se à capacidade que cada pessoa tem de criar códigos específicos dentro de uma determinada área, um beco, uma rua, uma viela. O sujeito também é capaz de decodificar tantos outros existentes na mesma. Assim, a mulher na cidade interage, compartilha, se apropria e se transforma.

Barros elucida que:

O grande texto urbano aloja dentro de si textos menores, feitos de placas de ruas que evocam memórias e imaginários, de cartazes que são expostos nas avenidas para seduzir e informar, de sinais de trânsito que marcam o ritmo da alternância entre a passagem permitida e os interditos aos deslocamentos no espaço. A cidade é um grande texto que tece dentro de si uma miríade de outros textos, inclusive os das pequenas conversas produzidas nos encontros $\operatorname{cotidianos}^{11}$.

A cidade, no sentido de ser formada por indivíduos, dialoga constantemente com as pessoas, tanto as que moram quanto as que passam somente de visita diariamente. Isso ocorre através de informações contidas em cartazes, placas e até mesmo dos monumentos existentes nela. De maneira singular cada sujeito decifra à cidade ao seu modo, apressa e

\footnotetext{
${ }^{10}$ BARROS, José D’Assunção Barros. Cidade e história. Petrópolis, RJ: Vozes, 2011.

${ }^{11}$ BARROS, José D’Assunção Barros. Cidade e história. Petrópolis, RJ: Vozes, 2011.
} 
diminui o passo, vivencia emoções e outras oportunidades.

Concomitante a esse pensamento, Matos, discute a cidade-documento ${ }^{12}$. Em que a paisagem urbana se coloca como um texto a ser lido, compreendido. Um documento a ser interpretado. A cidade passa a ser vista como espaço de disputa, tensões e representações. Passa a ser, também, objeto de investigação para o historiador.

Compreendida e percebida de múltiplas maneiras, a cidade se constitui como instrumento de legitimação do cotidiano. Nos variados espaços oferecidos por ela, carrega em si amontoados de significações, esboçam lembranças de uma infância que já se fora, memórias de um lugar ou evento que já não existe mais, cria e recria cotidianamente gestos, sensações, emoções, experiências e vivências.

Nesse sentido, Stella Bresciani, afirma que para estudar a cidade é necessário um olhar interdisciplinar, pois coloca que outros saberes surgem para lançar propostas no intuito de resolver os problemas da mesma. Discute também à questão fenomenológica do viver em cidade. O que não é palpável, visível, mas codifica e direciona o cotidiano dos sujeitos. Assim, a cidade comporta muitas cidades e fala da nossa afetividade. A sociedade se modifica e se redefine, encontra novas formas. O que antes estava pautado ao interior do lar, da família, vai aos poucos se tornando público. O viver acontece ${ }^{13}$.

Ao escrever sobre o cotidiano e a vida privada, Del Priore, discorre que "o imenso campo da vida privada e cotidiana se define como um lugar derivado de historicidade, mas, sobretudo, espaço produtor de história" ${ }^{14}$. Sua análise refere-se ao papel desempenhado pela mulher dentro da sociedade, sobretudo na brasileira, o que se percebe é uma paulatina inserção no espaço público, espaço esse que sempre foi ocupado pelos homens. À mulher aos poucos e através de muitas lutas vai deixando o espaço privado, mesmo que a princípio exerça um papel coadjuvante. A inserção da mulher não acontece apenas nos dias hodiernos, mas há muito tempo.

A sociedade se modifica e se redefine. O que antes estava pautado ao interior do lar, da família, vai aos poucos se tornando público. Para ela, tanto a vida cotidiana quanto a vida privada são definidas como espaços produtores de história. $\mathrm{O}$ viver se cotidianiza

\footnotetext{
12 MATOS, Maria Izilda Santos de. Cotidiano e cultura: história, cidade e trabalho. Bauru, São Paulo: EDUSC, 2002.

${ }^{13}$ BRESCIANI, Maria Stella. Cidade e História. In: OLIVEIRA, Lúcia Lippi. (Org.). Cidade: história e desafios. Rio de Janeiro: Ed. Fundação Getúlio Vargas, 2002.

${ }^{14}$ DEL PRIORE, Mary. História do cotidiano e da vida privada. In: CARDOSO, Ciro Flamarion; VAINFAS, Ronaldo. (Orgs.). Domínios da História: ensaios de teoria e metodologia. Rio de Janeiro: Campus, 1997.
} 


\section{Quando o partir se faz necessário}

Caro leitor, esse artigo é um fragmento de minha Dissertação de Mestrado, onde tive o privilégio de abordar as experiências de oito mulheres nordestinas que migraram para a região Norte, especificamente para o Amazonas chegando à cidade de Parintins.

A relação com a temática apresentada é de caráter subjetiva, visto que, também sou nordestina, natural de Recife-PE, e migrei há alguns anos na companhia de meu esposo Moacy para o Norte brasileiro. Ao chegar à cidade de Parintins-AM, fiquei surpresa, quando percebi uma presença significativa de nordestinos na mesma, o que despertou a curiosidade em saber sobre as motivações de tais vindas.

Durante a faculdade em Licenciatura em História, na ocasião da construção do projeto de pesquisa para TCC, uma inquietação sobre a presença dos nordestinos em Parintins veio à tona, comecei a procurar trabalhos acadêmicos sobre a temática e todos falavam, de forma geral, sobre a presença dos homens e as relações com o comércio, o que já era um contraponto com a historiografia tradicional que enfatizava às questões em torno da borracha.

Diante daqueles trabalhos surgiu uma questão: se há homens nordestinos em Parintins, há mulheres também. Afinal de contas, eu também sou nordestina e estou aqui! Não havia até aquele momento trabalhos com tal finalidade sobre a presença das mulheres nordestinas e suas motivações de estarem em Parintins. Fui em busca delas e as encontrei. Essa descoberta levou a construção do TCC e ao Mestrado.

Ao longo dessa caminhada tenho percebido que ao saírem de sua terra natal em busca de novas territorialidades, as mulheres nordestinas abrem caminhos, rompem com vínculos estabelecidos, encontram outros sujeitos e encaram novos desafios. Experimentam um mundo novo, socializam suas ações, ensinam e aprendem com quem está ao seu redor e, acima de tudo, vivem, agem e decidem.

Advindas de vários espaços nordestinos, cada qual com suas peculiaridades e motivações distintas, porém há um aspecto comum a todas, a congregação familiar. Todas as mulheres, sujeitos da pesquisa, partiram em função da junção de suas famílias. Algumas fizeram esse trajeto acompanhando os maridos, outras partiram com os filhos ainda pequenos no anseio de se encontrarem com os esposos que já estavam às suas esperas.

Nesse artigo, como representantes de um coletivo, trago às experiências de duas mulheres nordestinas. Foi no cotidiano de suas vivências que as encontrei, Maria de 
Fátima Xavier Paulo (63 anos) e Geralda Xavier Prado (88 anos). Os processos de relações com elas possibilitaram a construção desse estudo, em que os contatos com suas narrativas orais, somados ao contexto de suas ações, permitiram compreender numa palavra, através de um simples gesto como sorrir ou até mesmo chorar, detalhes que fizeram com que a experiência trocada se tornasse única.

Nesse ínterim, a decisão de partir em busca de trabalho e/ou outras possibilidades acontece dentro de uma teia social ${ }^{15}$. Essa por sua vez, está atrelada as redes de solidariedades e sociabilidades que se configuram e se (re)inventam diante e durante os deslocamentos. Dessa forma, a família, ou melhor, o arranjo familiar, tem se mostrado como o elemento primordial que motivou e movimentou Maria de Fátima Paulo e Geralda Xavier e tantas outras em seus percursos.

Entre às entrevistadas, percebi que a família, não só norteia a disposição de partir, mas também aparece como parte fundamental na tomada de decisão, de tal modo age sob a forma de um elo necessário entre os que vão embora e os que ficam. Assim, podemos entender esse elo em duas perspectivas de ação: o elo efetivo e o elo afetivo.

Por essa perspectiva em que a família se enquadra, não podemos dissociar uma relação da outra, não há como separar a efetividade e afetividade imbuídas na trajetória migratória. É necessário perceber a participação familiar como elo efetivo/afetivo uma vez que age como frente de apoio dando condições físicas e emocionais tanto na partida quanto na chegada, ela atua como suporte necessário na minimização das dificuldades dos contrastes impostos pelo deslocamento, isso quer dizer que ao partir, ocorre de certa maneia, um distanciamento dos costumes e hábitos herdados em que entra em contato e fusão com o novo lugar, o que antes era naturalmente praticado com a migração, passa a ser ressignificado.

Arranjos familiares esses que foram preponderantes nas trajetórias das mulheres que saíram de seus lugares de origem, sozinhas e/ou acompanhadas seguiram rumo a outros horizontes. As experiências trazidas por elas nos levam a refletir sobre seus anseios e angústias, suas impressões e perspectivas além dos medos e lutas que tiveram que vencer.

\footnotetext{
${ }^{15}$ Compreendendo uma teia social como conjunto de acontecimentos cotidianos. Sejam eles, de ordem econômica, política e social. Dessa forma, não há como explicitar dentro de uma única área do conhecimento um conceito fechado e definitivo, visto que, a amplitude das ações empreendidas por um ou mais sujeitos no corpo social é de caráter tanto multi quanto interdisciplinar.
} 
O sentido familiar é um fator de grande peso nas decisões que envolvem cada mulher entrevistada, de um lado há o apelo e todos os argumentos utilizados pelos pais, na maioria delas, para que não saíssem de perto de seus cuidados, em contrapartida, a constituição de suas próprias famílias, pelo menos para as que já haviam casado, é o determinante de suas saídas.

Maria de Fátima Xavier Paulo, saiu do Ceará depois de seu esposo e ao narrar sobre sua trajetória de vinda para o Norte, relembra da emoção sentida ao se despedir de seus pais. Ela conta que:

Eu senti muita emoção porque tava deixando meus pais. Não queria deixar meus pais. Eu me despedi dos meus pais, do meu pai da minha mãe e viajei pra cá. No início meu pai não queria que eu viesse. Ele disse que era muito longe o Amazonas, que andava muito, passava em muito buraco, ele não aceitava que eu vinha pra cá, mas depois eu falava: mas meu pai deixe eu ir que meu marido mandou me buscar, aí ele disse: não! fique minha filha que eu lhe crio e crio seus filhos. Ele não queria que eu viesse pro Amazonas, aí eu viajei com meus cinco filhos, graças a Deus. Aí minha cunhada falou pra ele: compadre deixe ela ir, que o marido mandou o dinheiro pra ela viajar e é ele que tem que criar os filhos. Mas o meu pai falou: eu criei ela e crio os filhos. Meu pai pedia pra que eu deixasse meu filho mais velho, eu disse que não, porque aí ia ser duas saudades ${ }^{16}$.

Sua saída do Ceará é marcada por um misto de sentimentos, em que de um lado encontra-se a dor de ter que deixar seus pais, e a certeza de que seu marido estava a sua espera juntamente com os filhos. Mesmo diante de todo o apelo feito pelo seu pai e do imaginário acerca da região amazônica, lugar de difícil acesso, como lugar em que as pessoas desapareciam, Fátima depara-se com um dilema a sua frente, ficar ou partir, eis a questão! Decidiu partir por mais difícil que lhe parecesse fazer.

Sem dúvidas, a família aparece como eixo central, assim como a ambiguidade da migração aparece em toda sua narrativa. Para ela, partir e ficar carregam o peso contraditório de parte dos familiares que queria sua permanência no lugar e o marido que a chama para seguir. Seu pai ao pedir que deixasse sob seus cuidados o filho mais velho, evidencia com isso a manutenção do vínculo familiar, mesmo a filha tendo que ir embora, o neto, seria ao seu ver o motivo de seu regresso. Não é o que acontece, ela parte e leva consigo os cinco filhos.

“Aí ia ser duas saudades", é a resposta que Fátima Paulo dá ao seu pai ao recusar sua proposta de deixar o filho mais velho. Um dos pontos marcantes de sua narrativa é o fato de que seu pai não queria que saísse. O apelo feito por ele está imbuído de medo de

\footnotetext{
${ }^{16}$ Maria de Fátima Xavier Paulo. Entrevista realizada em sua residência no dia 03 de dezembro de 2015.
} 
que a família sofresse uma separação, ou seja, o esfacelamento familiar significava desfazer os laços afetivos, por isso o pedido para que deixasse o filho. No entanto, ela teve que optar entre dois núcleos: família de origem e família construída - a raiz e a continuidade.

Com essa fala é possível afirmar que a migração é sem dúvidas uma experiência de saudades. Experiência essa que provoca uma ruptura na vida de todos os sujeitos que um dia, seja qual foi o motivo, partiu. Deixou na vida de tantos uma marca que só a saudade poderá preencher o vazio provocado pela ausência, que só é diminuído ou totalmente restabelecido com o possível retorno.

A saudade mencionada durante o momento da partida é um elemento que marcou profundamente sua vida. A lembrança da despedida até hoje é revivida com um brilho diferente no olhar, um misto de sentimentos é colocado em xeque, a vontade de partir em direção ao esposo é associada em grande medida à necessidade de sair de perto de sua parentela, esse drama na vida de Maria de Fátima, possibilita entendermos essa trajetória como experiência única, porém, vivenciada em contexto coletivo.

Ao discorrer sobre o seu percurso do Nordeste ao Norte, Maria de Fátima Paulo nos leva a pensar sobre o cotidiano que vivenciara durante o deslocamento, haja visto que:

\begin{abstract}
A gente veio do Ceará pra cá, nós viemos de ônibus até Belém. De Belém pra cá nós peguemos um navio, aquele navio da Inasa, que chamava de primeiro né! Eu vim de navio. Cinco dias, de lá pra cá é seis dias, sai terça aí chega aqui domingo à tarde. Eu ficava agoniadinha, pensava que meus filhos iam morrer, um adoeceu no caminho muito, aí quando chegou em Belém, aí eu falei: pronto meu filho vai morrer e vai rebolar dentro d'água, eu tava com ele doente e com medo de acontecer alguma coisa com ele. Aí eu consultei um médico antes de entrar no navio, o médico era médico e era espírita, sabe lá desses negócios de espírito né! Aí ele disse: olha aí dona Fátima não se preocupe que seu filho não vai morrer, dessa ele não vai morrer não só se for de outra doença, mas dessa seu filho vai ficar curado, passou um remédio aí eu dei, o menino que nem comer queria e já tava andando, ele tava com cinco anos de idade. Essa viagem foi muito longa assim, meus filhos adoeceram muito dentro do navio, provocaram muito, o navio bambeava muito, agora que não bambeia mais, aí no começo só faltava virar, aí era muita gente desmaiada, até o povo grande, provocava muito, desmaiada, e aí que tanto provocava, coisava tanto, , e o medo que eu tinha, um filho já adoeceu e o povo dizia: não é assim não! não é assim não. E graças a Deus eu cheguei em Óbidos, que dessa primeira vez eu fui pra Óbidos, eles era tudo pequenos, tinha um com sete anos, outro tinha seis, outro tinha cinco, outro tinha quatro e tinha um com um ano e cinco meses que era o caçula. De Óbidos pra cá (Parintins) foi mais tranquilo né! Que a viagem é mais perto e já tavam um pouco mais velho ${ }^{17}$.
\end{abstract}

\footnotetext{
${ }^{17}$ Maria de Fátima Xavier Paulo. Entrevista realizada em 03 de dezembro de 2015.
} 
O medo e a coragem são elementos marcantes em todo o trajeto percorrido por Fátima. Primeiro pelo fato de que fazendo esse deslocamento com cinco filhos pequenos, a primeira etapa ocorreu de ônibus até Belém, percurso tal que se comparado aos moldes de nossa atualidade, com ônibus equipados com um considerável grau de conforto, ainda assim leva alguns dias para que seja concluído com sucesso. Agora, pensar essa mesma viagem sendo realizada há quase trinta anos, não é difícil imaginar as circunstâncias vivenciadas por ela e suas crianças. Tanto é que uma adoeceu!

"O navio bambeava muito", mesmo o filho tendo se refeito do mal-estar que contraiu no percurso feito de ônibus, o movimento feito pelo navio causou grande preocupação a Fátima, preocupação não só pelo fato do garoto voltar a adoecer, mas um medo que lhe parecia real, o de vir a falecer e ser jogado na água. A sequência de "males" provocado pelo balanço do navio em que tanta gente seja ela pequena ou "povo grande" passara nesse trajeto tornara-se insignificante diante da possibilidade de vir a perder um filho seu. O que não ocorreu.

E mais, ela conta que:

\begin{abstract}
Quando eu saia às vezes eu mandava vigiar, quando ia tomar banho, os meninos ficava deitadinho, eu dizia: vigia aí, mandava a mais velha, quando ela tava dormindo, eu dizia: vizinha olha aí enquanto eu vou lá no banheiro tomar um banho, ela dizia: tá bom pode ir, pode ficar despreocupada que eu olho. Eu vim na rede, era rede por cima de rede, era seis rede atada, foi uma viagem boa, não foi toda boa porque meus filhos adoeceram no caminho, lavava os panos, eu trazia pedaço de sabão, eu ando com tudo preparado né, viajava com criança né! Lavava as roupinhas deles, todo dia eu lavava e estendia os lençol deles, e quando eles mijavam. Ainda bem que não era uma redinha de pobre, era uma redinha nova né! Porque lá no nordeste é assim, meus filhos tudo era pequeno, mas graças a Deus pra uma pobre as redes dos meus filhos era uma rede de quem era controlada (econômica), eu tinha as redinhas deles usarem em casa e umas de quando a gente sair ter as redes que eu guardava, que era as redes boa, aí as redes dos meus filhos lá no nordeste eu fazia, eu gostava de fazer com aqueles panos de saco, sabe aqueles panos de saco? Bem branquinho! Aí eu mandava botar o meio.
\end{abstract}

O cuidado com os filhos é bastante notório em sua narrativa, sobretudo, durante os percursos traçados. É interessante que as redes utilizadas como suporte necessário nas viagens realizadas de barco, na fala de Fátima Paulo, aparecem também, como símbolos de distinção social, como ela afirma que "ainda bem que não era uma redinha de pobre, era uma redinha nova né!”. Diferenciar os tipos das redes usadas na viagem evidencia o fator socioeconômico incutidos em se apresentar em um outro espaço social, não queria que seus filhos usassem as mesmas redes que tinham quando ainda estavam no Nordeste. Ao seu ver, isso poderia ser compreendido como algo feio, inadequado. Não queria expor 
seus filhos a qualquer tipo de julgamento. E assim, Maria de Fátima chegou ao seu destino, ao encontro do seu esposo, conseguiu reunir novamente a família.

Geralda Xavier, que é tia de Maria de Fátima, já residia em Parintins quando sua sobrinha chegou. Embora não tenha aparecido na narrativa de Fátima como um elo efetivo de sua vinda, é mencionada a partir do momento que Fátima afirma que já havia alguns parentes morando em Parintins, já tinha o conhecimento de que havia tias na cidade, dentre elas Geralda. E sobre sua vinda elucida que:

\begin{abstract}
Vim pra acompanhar meu esposo. Meu esposo veio primeiro. Aí eu fiquei com cinco filhos, aí meu esposo mandou dizer que eu viesse de barco, aí minha cunhada que me amava muito, falou que de barco ela não vai. Ligou pro cunhado aqui (Ceará) que era irmão do esposo que morava em Manaus era riquíssimo, um grande comerciante, que mandasse a passagem de avião que eu não saía de lá com cinco filhos pra vim de barco, de navio, aí eu vim de avião, quando cheguei em Belém, os filhos tudo provocando, tudo passando mal, aí chegaram e disseram pra mim, o piloto disse: olhe a senhora não tem condições de viajar, eu disse: mas também não tenho condições de ficar aqui com esses bandinhos ${ }^{18}$, aí eu disse: ou vivendo ou morrendo eu vou pra Manaus! Eu quero chegar em Manaus hoje, graças a Deus! Cheguei com os filhos tudo baquiado, só a viagem que foi difícil, quando cheguei gostei do lugar, de Manaus, agradeci muito a Deus, que tudo eu achava bom, que morava no interior! Fui morar na capital, achei tudo bom! Mas passamos tantos problemas, mas venci! 19
\end{abstract}

É interessante perceber na fala de Geralda três aspectos relevantes que motivaram sua vinda. O primeiro, é a constituição familiar que impulsionou seu deslocamento do interior do Ceará rumo ao Amazonas, trazendo consigo os cinco filhos. O segundo é a ênfase que ela dá a postura de sua cunhada em sua defesa, onde articula a vinda de avião. Aqui se percebe que a situação financeira de seus familiares era bastante diferenciada no que tange uma boa parcela de nordestinos que também migraram na mesma época ou aproximadamente. Custear uma passagem de avião em plena década de 1950, não era tão simples e nem barato!

Até porque se fôssemos levar em consideração o cenário sócio-político do Brasil nos anos de $1950^{20}$, a conjuntura das regiões Norte e Nordeste pouco viabilizava que sujeitos oriundos do interior nordestino e que não possuíam nenhuma atividade de grande porte tivessem uma eventual ascensão econômica. No entanto, Geralda tinha um cunhado

\footnotetext{
${ }^{18}$ Expressão trazida por Geralda Xavier ao se referir aos filhos.

${ }^{19}$ Geralda Xavier Prado. Entrevista realizada em 17 de novembro de 2016.

${ }^{20}$ Essa fala de Geralda nos leva a pensar que o Amazonas nessa época passava por um conturbado período de recessão, no entanto seu cunhado que sai do Nordeste estabelece moradia e comércio em Manaus enriquece. Djalma Batista em seu livro Complexo da Amazônia (2007) discute sobre os diferentes momentos econômicos que não só a região, sobretudo o estado do Amazonas enfrenta até a criação e implementação da Zona Franca de Manaus que só ocorre nos anos finais da década de 1960.
} 
que na época de seu deslocamento era "riquíssimo", um grande comerciante como ela mesma menciona. Isso em Manaus, o que certamente viabilizou sua vinda e de seus filhos de avião.

“Os filhos tudo baquiado", o terceiro aspecto, é a compreensão que Geralda faz sobre o mal-estar provocado pela viagem aos filhos, mesmo assim, quando indagada pelo piloto sobre a condição de saúde deles em prosseguir viagem, não hesitou em responder que não ficaria em Belém. Essa atitude de Geralda em querer chegar ao seu destino demonstra sua obstinação, ou melhor, a possibilidade de ficar em Belém é sinal de desespero, o que iria fazer em Belém? Com quem iria ficar? Ela precisava chegar em Manaus, pois lá estava sua sustentação e referência. Queria chegar logo ao encontro de seu esposo, pois preocupava-se com a situação de vulnerabilidade em que os filhos se encontravam, diante disso, foi enfática ao afirmar que "vivendo ou morrendo", a parada final não seria Belém como propunha o piloto, e sim Manaus.

O encantamento proferido por Geralda faz menção a sua trajetória de saída do interior do Nordeste, local onde havia morado praticamente sua vida toda. A migrante, nunca havia estado em uma cidade grande como Manaus, o que a fez se surpreender em estar numa capital, e mais, todo o transtorno vivido na viagem parecia quase inexistente diante do novo momento que estava experimentando. E, afinal de contas, a família estava mais uma vez reunida.

\section{Migração e História Oral - Algumas Considerações}

A experiência migratória marca suas vidas entre processos de (des)continuidades e rupturas, uma vez que, novas situações de conflitos ou não, entrelaçam suas vivências. O sentimento em relação ao novo espaço, provoca uma necessidade que até então não havia sido experimentada por nenhuma das mulheres, tal necessidade pode ser compreendida a partir das narrativas quando o migrante, na perspectiva de Marandola:

Sente a necessidade de fixar-se para poder alcançar uma sensação de bemestar, aliviando o incômodo sentimento de incerteza e instabilidade que perdura e se reforça com a ausência do lugar. No entanto a fixação do migrante no local de destino tem algumas restrições ou condições em termos de identificação sociocultural e espacial. O envolvimento de um indivíduo com o lugar é um processo complexo que não ocorre aleatoriamente ${ }^{21}$.

${ }^{21}$ MARANDOLA Jr, E. \& DAL GALLO, P.M. Ser migrante: implicações territoriais e existenciais da migração. R. brasil. Est. Pop., Rio de Janeiro, v. 27, n.2, 2010. 
Em relação à fixação do migrante não ocorrer de forma aleatória destacamos que isso é fruto de alguns fatores, dentre eles os laços afetivos que vão sendo consolidados durante todo o processo. Assim, as redes afetivas ou de sociabilidades vão sendo alicerçadas nos locais onde um ou mais sujeitos estão dispostos. E práticas que até então só eram comuns no lugar de origem entram em fusão com as práticas sociais trocadas no lugar de destino. E, a partir dessas trocas, há uma profunda transformação na vida desses sujeitos.

Nessa intenção de visibilizar a trajetória dessas mulheres nordestinas, levamos em consideração a complexidade presente nas particularidades trazidas pelas memórias, compreendendo com Maurice Halbwachs, que essas memórias mesmo sendo colocadas no âmbito individual (retalhos de um todo) negociam o tempo todo com as memórias coletivas. Essa, é, portanto, a costura da "colcha de retalhos" que compõe o tecido social ${ }^{22}$.

Em outras palavras, Alessandro Portelli chama atenção para que possamos compreender as fontes orais como ato político ${ }^{23}$. Ainda mais que as memórias das mulheres mencionadas nesse estudo, permitam traçar um panorama acerca de suas vivências, de suas trajetórias e de como elas se inscrevem na dinâmica social de Parintins, desde o momento de sua saída do Nordeste.

Ao fazer uso da subjetividade do sujeito, a fonte oral contribui principalmente no questionamento da fonte escrita, rompendo com o estabelecido e apontando outro olhar na forma como os sujeitos percebem e interpretam seus modos de vida. Para Portelli “[...] a subjetividade se revelará mais do que uma interferência; será a maior riqueza, a maior contribuição cognitiva que chega a nós das memórias e das fontes orais" ${ }^{24}$. Segundo esse mesmo autor, é através da subjetividade que o sujeito atribui significado a sua experiência. Não é o fato ocorrido em si, mas o significado atribuído a ele que faz toda diferença.

No bojo dessa discussão, tratamos também outro aspecto de suma relevância para que tenhamos uma dimensão ainda maior das vivências dessas mulheres nordestinas em Parintins que é a "experiência" trazida por Thompson. Para ele, "a experiência surge espontaneamente no ser social, mas não surge sem pensamento. (...) Assim como o ser é pensado, também o pensamento é vivido" ${ }^{25}$. Isso indica que a experiência dos sujeitos no corpo social é, também, refletida por eles.

Mesmo tendo em comum o espaço e o tempo recortado nesse estudo, percebe-se que o tempo da memória juntamente com as experiências vividas por essas mulheres mencionadas aqui, ocorre de maneira singular para cada uma. Assim, a construção histórica dessa temática caminha interligada com a história, a memória e o tempo narrado por elas, já que o tempo da memória se difere do tempo vivido.

\footnotetext{
${ }^{22}$ HALBWACHS, Maurice. A memória coletiva. São Paulo: Centauro, 2006.

${ }^{23}$ PORTELLI, Alessandro. História Oral e Poder. In: Mnemosine. Vol. 6, n 2 2, p. 3 (2010). Artigos

${ }^{24}$ PORTELLI, Alessandro. A Filosofia e os Fatos: narração, interpretação e significado nas memórias e nas fontes orais. Tempo, Rio de Janeiro, vol. 1, n. 2, 1996.

${ }^{25}$ THOMPSON, E. P. A miséria da teoria: ou um planetário de erros. Rio de Janeiro: Zahar, 1981.
} 
Nesse sentido, Ecléa Bosi em seu livro Memória e Sociedade de 1994, discorre que a ativar a memória "é o momento de desempenhar a alta função da lembrança". Sendo que a partir das memórias orais dessas mulheres nordestinas, é possível reconstruir processos históricos, onde "um mundo social que possui uma riqueza e uma diversidade que não conhecemos pode chegarnos pela memória dos velhos. Momentos desse mundo perdido podem ser compreendidos por quem não os viveu e até humanizar o presente". A essa reconstrução de um dado processo histórico, segundo Ecléa Bosi, está diretamente relacionada com a função social da memória, e salienta que, "a conversa evocativa de um velho é sempre uma experiência profunda: repassada de nostalgia, revolta, resignação pelo desfiguramento das paisagens caras, pela desaparição de entes amados, é semelhante a uma obra de arte"26.

A lembrança dos velhos semelhante a uma obra de arte na afirmação de Ecléa Bosi faz pensar no diálogo existente entre o presente e o passado mediante ao ato de lembrar, um diálogo que é vivo, pois a memória não está presa ao tempo de vida de um sujeito, "ela ultrapassa esse tempo de vida individual e encontra-se com o tempo da História"27. Nesse entendimento, História, Memória, Tempo Vivido e Tempo Lembrado caminham juntos.

Delgado discute, entre outros pontos relevantes sobre Tempo e História, que há uma distinção entre o tempo da memória do tempo histórico, onde a memória além de ser múltipla por sofrer constantes alterações, ela é uma reação do vivido, pois está enquadrada em três dimensões: a coletiva, a individual e a histórica. A história tem o papel de representar um dado fenômeno e busca as informações contidas na memória para realizar sua tarefa.

Maurice Halbwachs, indica que a memória não está dissociada de um tempo e de um espaço para que às lembranças de um dado evento vivido venha à tona na rememoração de uma pessoa. Assim, mesmo que a memória coletiva contenha a memória individual, uma não existe sem a outra. Segundo o autor mencionado acima, "nossa memória não se apoia na história, mas na história vivida".

Diante disso, dizemos que a memória faz menção a um período registrado nas vidas dessas mulheres nordestinas, pois o tempo é um elemento relevante nessa constituição, uma vez que ele ocorre dentro de um movimento dinâmico relacionado às vivências de cada ator social, em que carrega em si as rupturas, permanências e continuidades que permeiam as experiências de vida de cada uma das mulheres descritas nesse estudo.

\footnotetext{
${ }^{26}$ BOSI, Ecléa. Memória e Sociedade: lembranças dos velhos: 3 ed. São Paulo: Companhia das Letras, 1994.

${ }^{27}$ DELGADO, Lucíola de Almeida Neves. História oral - memória, tempo, identidades. Belo Horizonte: Autêntica, 2006.
} 


\section{Considerações Finais}

A postura das mulheres aqui mencionadas contesta o papel imposto para a mulher durante muito tempo, elas decidem, agem e rompem paradigmas estabelecidos. Defendem e lutam pelo que acreditam. Saem do silêncio e do esquecimento histórico. As ações

engendradas por Maria de Fátima Xavier Paulo e Geralda Xavier Prado, trazidas como representantes de um coletivo, apontam formas de resistência em busca de ajuda e consolo, mesmo em momentos distintos. Representam ações de autonomia, liberdade e esperança em expressar os seus anseios e angústias. Elas exercitam cada uma à sua maneira e à medida do possível, seus espaços de poder.

Esse estudo coloca a mulher como sujeito que é ativo, social e histórico na dinâmica de seus processos migratórios. E, que muitas das vezes mesmo dentro de seus afazeres cotidianos, a participação no espaço público se confunde com o privado e vice e versa, suas memórias materializadas em vivências e estas transformadas em experiências contribuem na construção de novas histórias na Amazônia, a partir de Parintins.

A forte influência familiar nas narrativas evidencia que os motivos de sair do Nordeste, estão atrelados diretamente as questões afetivas, sem desconsiderar as questões socioeconômicas que as envolviam. Saíram porque já havia alguém esperando na chegada. Saíram porque os que vieram primeiro fizeram esse percurso em busca de trabalho, em busca de novas perspectivas. Ao conseguirem, permitiram e possibilitaram a vinda dos parentes, a vinda das mulheres sujeitos dessa pesquisa.

Escrever a história, especialmente a do tempo presente, nos permite caminhar na trama do vivido por essas mulheres nordestinas. Sujeitos que trazem consigo as marcas das experiências vividas. Essas mulheres carregam na bagagem de suas vidas a construção de suas histórias, ao relembrarem um dado acontecimento, elas revivem e, nesse ato de reviver, estão mais uma vez "construindo sentidos" 28 ou melhor, possibilitam na (re)escrita da História a partir de suas vivências.

Temos a compreensão de que cada sujeito é capaz de dar sentido à própria existência por meio da sua própria narrativa, por sua maneira de perceber o mundo em que vive e de que maneira age e se percebe nele. Diante disso, é possível afirmar que cada um tem sua história, ou melhor, a história de cada mulher nesse trabalho está relacionada a vários aspectos: econômicos, políticos, religiosos, cultural, sobretudo, está relacionada aos aspectos sociais da realidade em que estão inseridas.

\footnotetext{
${ }^{28}$ SILVA, Patrícia Rodrigues da. Disputando espaço, construindo sentidos: vivências, trabalho e embates na área da Manaus Moderna (Manaus/AM - 1967 - 2010). Manaus: EDUA, 2016.
} 
Maurice Halbwachs juntamente com Michael Pollak ${ }^{29}$ contribuem no entendimento de que a memória é socialmente construída e constituída de acordo com aspectos de ordem identitária de cada sujeito. Chamar à tona a memória das mulheres nordestinas é sem dúvidas, compreender seus contextos sociais, porque elas falam sobre suas histórias e, estas narrativas, não estão dissociadas de um espaço e de um tempo.

Os arranjos familiares foram preponderantes nas trajetórias das mulheres que saíram de seus lugares de origem, sozinhas e/ou acompanhadas seguiram rumo a outros horizontes. As experiências trazidas por elas nos levam a refletir sobre seus anseios e angústias, suas impressões e perspectivas, além dos medos e lutas que tiveram que vencer.

Assegurar a coesão familiar se coloca para elas como um elemento de unidade. É o espaço identitário, em nome do qual vale a pena empreender todas as suas lutas. Configura-se como um elo de cunho coletivo.

Data de submissão: 07/05/2020

Data de aceite: 15/07/2020

${ }^{29}$ POLLAK, Michael. Memória e identidade Social. Estudos Históricos, Rio de Janeiro, vol. 5, n. 10, 1992. 


\section{Fontes Orais}

PAULO, Maria de Fátima Xavier. Entrevista realizada em sua residência em 03 de dezembro de 2015. A entrevista foi feita por Patrícia Regina de Lima Silva.

PRADO, Geralda Xavier. Entrevista realizada em sua residência em 17 de novembro de 2016. A entrevista foi feita por Patrícia Regina de Lima Silva.

\section{Referências Bibliográficas}

BARROS, José D’Assunção Barros. Cidade e história. Petrópolis, RJ: Vozes, 2011.

BASSANEZI, Maria Sílvia. Mulheres que vêm, mulheres que vão. IN: PINSKY, Carla Bassanezi; PEDRO, Joana Maria. Nova História das mulheres no Brasil. 1 ed. São Paulo: Contexto, 2013.

BATISTA, Djalma. O complexo da Amazônia - análise do processo de desenvolvimento. 2 ed. Manaus: Editora Valer, Edua e Inpa, 2007.

BOSI, Ecléa. Memória e Sociedade: lembranças dos velhos: 3 ed. São Paulo: Companhia das Letras, 1994.

BRESCIANI, Maria Stella. Cidade e História. In: OLIVEIRA, Lúcia Lippi. (Org.). Cidade: história e desafios. Rio de Janeiro: Ed. Fundação Getúlio Vargas, 2002.

CHAVES, Maria de Fátima Guedes. Mulheres migrantes: senhoras de seu destino? Uma análise da migração interna feminina no Brasil: 1981 - 1991. São Paulo, 2009, p.14. Tese (doutorado) - Universidade Estadual de Campinas - Departamento de Demografia - Instituto de Filosofia e Ciências Humanas. Disponível na biblioteca digital da Unicamp.

DELGADO, Lucíola de Almeida Neves. História oral - memória, tempo, identidades. Belo Horizonte: Autêntica, 2006.

DEL PRIORE, Mary. História do cotidiano e da vida privada. In: CARDOSO, Ciro Flamarion; VAINFAS, Ronaldo. (Orgs.). Domínios da História: ensaios de teoria e metodologia. Rio de Janeiro: Campus, 1997.

HALBWACHS, Maurice. A memória coletiva. São Paulo: Centauro, 2006.

LACERDA, Franciane Gama. Migrantes cearenses no Pará: faces da sobrevivência (1889 - 1916). Belém: Ed. Açaí/Programa de Pós-graduação em História Social da Amazônia (UFPA) / Centro de Memória da Amazônia (UFPA), 2010.

LANG, Alice Beatriz da Silva Gordo. História oral e migração: a questão do regresso. Oralidades: Revista de História Oral, 2. 2007.

MARANDOLA Jr, E. \& DAL GALLO, P.M. Ser migrante: implicações territoriais e existenciais da migração. R. brasil. Est. Pop., Rio de Janeiro, v. 27, n.2, 2010.

MATOS, Maria Izilda Santos de. Cotidiano e cultura: história, cidade e trabalho. Bauru, São Paulo: EDUSC, 2002. 
PEREIRA, José Carlos Alves. O lugar desmanchado, o lugar recriado? Enredos e desenredos de jovens rurais na migração internacional. Campinas, 2012. Tese (doutorado) - Programa de Pós-Graduação em Sociologia - Instituto de Filosofia e Ciências Humanas da Universidade Estadual de Campinas - SP.

POLLAK, Michael. Memória e identidade Social. Estudos Históricos, Rio de Janeiro, vol. 5, n. 10, 1992.

PORTELLI, Alessandro. A Filosofia e os Fatos: narração, interpretação e significado nas memórias e nas fontes orais. Tempo, Rio de Janeiro, vol. 1, n. 2, 1996.

PORTELLI, Alessandro. História Oral e Poder. In: Mnemosine. Vol. 6, nº 2, p. 3 (2010). Artigos.

REIS, Arthur Cezar Ferreira. O Seringueiro e o Seringal. Ed. do serv. de Informação Agrícola, série Documentário da Vida Rural (5). Rio de Janeiro. Serv. Graf. Ibge, 1953.

SILVA, Patrícia Rodrigues da. Disputando espaço, construindo sentidos: vivências, trabalho e embates na área da Manaus Moderna (Manaus/AM - 1967 - 2010). Manaus: EDUA, 2016.

THOMPSON, E. P. A miséria da teoria: ou um planetário de erros. Rio de Janeiro: Zahar, 1981. 